\title{
Health Impact of Community-Based Water Treatment Systems in Honduras
}

\author{
Jeffery Deal \\ Health Studies at Water Missions International, 2049 Savannah Highway, Charleston, SC 29407, USA \\ Correspondence should be addressed to Jeffery Deal, jdeal@watermissions.org
}

Received 1 November 2011; Accepted 30 November 2011

Academic Editor: Kaushik Bose

Copyright () 2011 Jeffery Deal. This is an open access article distributed under the Creative Commons Attribution License, which permits unrestricted use, distribution, and reproduction in any medium, provided the original work is properly cited.

This paper provides a followup on a previous report in this journal on the health impact of providing access to water treatment and flush toilets to region of Honduras. Significant reductions were found in the one-year incidence of positive test results for the three protozoan species tested. This finding combined with the previously reported ethnographic and medical chart review data provides compelling evidence that such interventions significantly reduce the disease load from waterborne pathogens within this population. Furthermore, the finding that initial results are significantly different, even in the initial round of testing, if individuals who are not followed up are eliminated from the analysis has profound methodological implications which warrant further investigation and demonstrates the need for precise definitions of community in future studies.

\section{Introduction}

A key component of the United Nations Millennium Development Goal Number 7 states "halve, by 2015 the proportion of the population (global) without sustainable access to safe drinking water and basic sanitation." Most waterborne diseases result in diarrhea which continues to be a leading cause of morbidity and mortality worldwide. According to World Health Organization data, using existing technologies approximately ten percent of the worldwide burden of disease would be removed by the water supply, sanitation, hygiene, and management of water resources, making waterrelated diseases arguably the most manageable set of health problems affecting humans [1].

A great deal of work has been done attempting to measure the impact of interventions to provide improved water sources at the household level, and less frequently at the community level. The overwhelming majority of these studies have also used either key informant or self-reporting of diarrhea (defined as three or more loose stools per day) as the measure of disease burden [2-4]. Reliance upon such nonobjective measures introduces a host of potentially confounding variables $[2,5,6]$ and yet appears to have been used in all of the 2,120 published studies reviewed in a far reaching meta-analysis produced for the World Bank on diarrhea and water interventions [7]. While some of these deficiencies may be reduced by shortening recall time to seventy-two hours or less, potentially profound observer effects remain. Estimates of disease load changes are further impeded by researchers' concentration on known users of water systems rather than measurements on community disease levels of disease changes regardless of compliance, thus making extrapolations of disease rate changes inappropriate.

In 2006, Water Missions International (WMI) received a grant from the Pentair Foundation to provide improved water source access and toilet systems to all of the people in the district of Colon, Honduras, an area that contains approximately 340,000 people. The goal of $100 \%$ coverage utilizes a combination of solutions including homebased filtration systems (provided by a different NGO) for communities with less than 300 people, and a variety of high-capacity treatment systems for larger communities. In the initial phase of the study, all 604 water sources for the control and test communities were tested by pressure filtration methods, and all failed quality testing by being positive for coliform bacterial growth. For all households that lacked adequate sanitation facilities and agreed to assist in installation, sanitary pit latrines with pour-flush toilet (toilets with water traps and no reservoir that are flushed by pouring a bucket of water into the basin) were also provided. 
Water treatment systems and pour-flush toilets deployed during the present study were developed and manufactured by Water Missions International, a nonprofit organization based in Charleston, SC, that works to provide sustainable water treatment capacities and sanitation facilities for people in developing countries. The technology uses a combination of multimedia, multistage filters, and chlorination to provide treated water for drinking and cooking that meets the most stringent class of WHO drinking water standards as well as passed present US standards from the EPA-specifically, tests on treated water grew no coliform bacteria on repeated, monthly testing during the period of this study. In addition, WMI provides community development programs that include education and microenterprise strategies to assure sustainability of these interventions.

In the baseline study phase of the project, water sources for 613 communities were identified. Various water quality tests were conducted on the community water sources by standard membrane filter test. High counts of coliform bacteria indicative of fecal contamination were found in $100 \%$ of the water sources. As previously published [8], initial stool tests also showed that $29.3 \%$ (53 of 181) of the volunteer subjects from the twelve communities that had been randomly selected from the state of Colon carried at least one of the three tested protozoan parasites. Also as reported previously, the prevalence of positive protozoan parasite levels was significantly lower in the intervention groups as compared to the test group. Even greater reductions of disease rates (at least 52\%) were noted in the medical chart reviews of visits to the local health facility for diarrhea and dysentery as well as self-reporting of the same diseases via ethnographic interviews. Ethnographic data further suggested widespread acceptance and communitywide reproduction of the awareness of health benefits derived from consuming treated water. The present paper is a followup to that report primarily looking at the development of positive parasite stool tests in the same communities twelve months after the initial round of tests with an expanded study population.

\section{Methods}

Twelve communities from three different categories were randomly selected from the Colon district. Four communities had not yet obtained a water treatment system and were used collectively as the Control Group. Four other communities where water systems (Water Only Group) had been deployed were entered into the study as were four more communities where both water systems and sanitary flush latrines had been installed (Water and Sanitation Group). For both the initial tests in 2009 and the final round of tests in 2010, volunteers were recruited by poster advertising and via community leaders. Methods of recruitment were identical in all communities. All subjects who tested positive for protozoan antigens in either study (2009 or 2010) were treated with an appropriate dose of tinidazole $(500 \mathrm{mgs}$ per day for three days for adults with weight adjusted dosing for children). Subjects were directly observed to take the initial dose, which in management of Giardia has been shown to be highly effective without the additional doses. No side effects of treatment were reported. One hundred and sixty-three of the 200 subjects in the final round of testing in 2010 had also participated in the prior studies conducted 12 months earlier.

The effect of previous medical treatment of subjects upon the present study is to provide a population that either tested negative or were given highly effective treatment in 2009thus providing a subpopulation which was believed to have begun the 12-month test period free of any of the three tested protozoans. The results among the subjects tested both times, therefore, may be regarded as the rates of reinfection over the 12 -month period (or a one-year incidence rate) for all three groups.

Recent advances in highly sensitive and specific rapid immunoassays for waterborne parasite diseases have made field testing of individual fecal specimens now possible $[9,10]$. These devices test for species-specific antigens of common parasites known to be primarily waterborne. The device chosen for this study tested for three protozoan parasites: Giardia lamblia (now widely known as Giardia intestinalis), Entamoeba histolytica/Entamoeba dispar, and Cryptosporidium parvum antigens. Previous work has shown these tests to have both specificity and sensitivity in excess of $96 \%$ for the aforementioned pathogens.

Immunoassay of stool for these waterborne parasites was used as an indicator that the subject had been exposed to waterborne pathogens and was therefore at risk of these and other infectious waterborne illnesses. A separate subset of 163 subjects from the three groups who also gave specimens twelve months earlier was analyzed as a separate subgroup. Given the highly effective cure rates of tinidazole for Giardia and Entameba and the fact that the vast majority of nonimmunocompromised subjects will clear Cryptosporidium infections spontaneously, this subset is thought to represent recolonization rates with waterborne protozoan during the year after the initial round of testing and treatment. All specimens were tested within 12 hours of collection using the Triage Micro Parasite Panel manufactured by Biosite Incorporated.

Further information regarding diarrhea and dysentery rates was obtained by reviewing medical records from a public health clinic in a community where a water treatment system had been previously installed. Ethnographic data was collected using a combination of KAP surveys and guided interviews. The medical records review and the majority of the ethnographic data have been previously reported in this journal [8].

\section{Role of the Funding Source and Ethics Review}

Water Missions International maintains a country program in Honduras whose staff provided support and significant amount of labor for this project. The study design, collection, and analysis of data and interpretation of the data were the sole responsibility of the author.

Prior to initiation of the study, the Colon Minister of Health and the Institutional Review Board of Water 
TABLE 1: Age distribution of all subjects in all groups.

\begin{tabular}{ccccc}
\hline & Min. & Max. & Mean & Std. deviation \\
\hline Age & 2 & 82 & 23.06 & 19.143 \\
\hline
\end{tabular}

TABLe 2: Mean age distribution by group.

\begin{tabular}{lccc}
\hline & Mean (years) & $N$ & Std. deviation \\
\hline Control group & 22.67 & 67 & 18.806 \\
Water only group & 24.79 & 68 & 20.662 \\
Water and sanitation group & 21.66 & 65 & 17.959 \\
\hline
\end{tabular}

TABLE 3: Gender by intervention group.

\begin{tabular}{lcccc}
\hline & Control group & $\begin{array}{c}\text { Water only } \\
\text { Group }\end{array}$ & $\begin{array}{c}\text { Water and } \\
\text { sanitation group }\end{array}$ & Totals \\
\hline Female & 44 & 42 & 39 & 125 \\
Male & 23 & 26 & 26 & 75 \\
\hline Total & 67 & 68 & 65 & 200 \\
\hline
\end{tabular}

TABLE 4: 2010 data comparing control group to the combination of water only group and water and sanitation group.

\begin{tabular}{lccc}
\hline & Controls & $\begin{array}{c}\text { Combined water } \\
\text { only and water and } \\
\text { sanitation }\end{array}$ & Totals \\
\hline Negative for any parasite & 50 & 126 & 176 \\
Positive for any parasite & 17 & 7 & 24 \\
\hline Total & 67 & 133 & 200 \\
\hline
\end{tabular}

Missions International reviewed and gave approval and consent for the project and study. Consistent with this review, no information from medical chart reviews which could identify subjects of the study was retained outside of the local healthcare facility. Under the supervision of a licensed physician, all individuals in whom potential pathologic parasites were found were given free treatment with regimens previously approved by the Colon Minister of Health. The control communities where no water treatment or sanitation facilities existed were selected from a preexisting construction queue and intervention was not withheld as a result of this study. Verbal consent was obtained and recorded from all subjects.

\section{Results}

Age distributions within the three groups are seen in Tables 1 and 2. Gender distribution is seen in Table 3. Parasite test results for the control group compared to the combined water only group and water and sanitation group are seen in Table 4. Giardia and Entameba accounted for all but one positive test in all categories. Giardia accounted for $46 \%$ and Entameba $48 \%$ of the positive tests while Cryptosporidium remained rare at $6 \%$ of the totals.

Subjects living in communities that did not have access to water systems had significantly higher rates of positive tests than subjects who had either access to water or who had

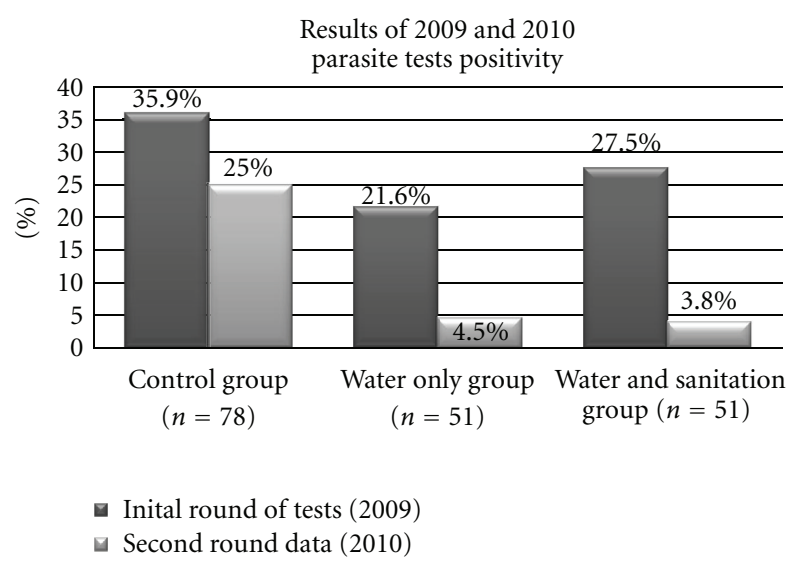

Figure 1

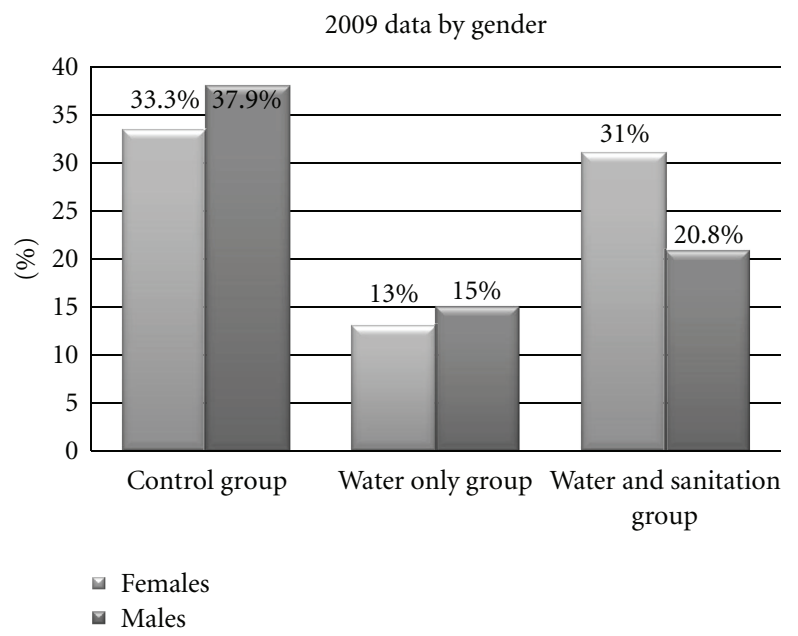

FIgURe 2

access to water and flush toilets both in the initial survey of 2009 and in the 2010 followup $(P<.005)$. These finding are summarized in Figure 1.

In 2009, a comparison of the rate of positive parasite tests appeared to demonstrate that, while access to a water treatment system reduced parasite levels, communities that had both treatment systems and installed flush toilets demonstrated a higher rate of positive parasite tests. These findings show a distinct gender bias toward women and are summarized in Figure 2. Additional ethnographic witnessing suggested that this finding may possibly be explained by the fact that women exclusively cleaned the toilets, often with inadequate supplies and protection. Water Missions International responded to this suggestion with additional training and supplies. In the followup parasite survey of 2010, what had appeared to have been a negative effect of the toilet systems was no longer present, as seen in Figure 2.

A separate analysis of parasite test results including only subjects who were available in both 2009 and 2010 is summarized in Figure 3. Of interest is that the apparent negative effect of the toilets in the 2009 data (Figure 1) 


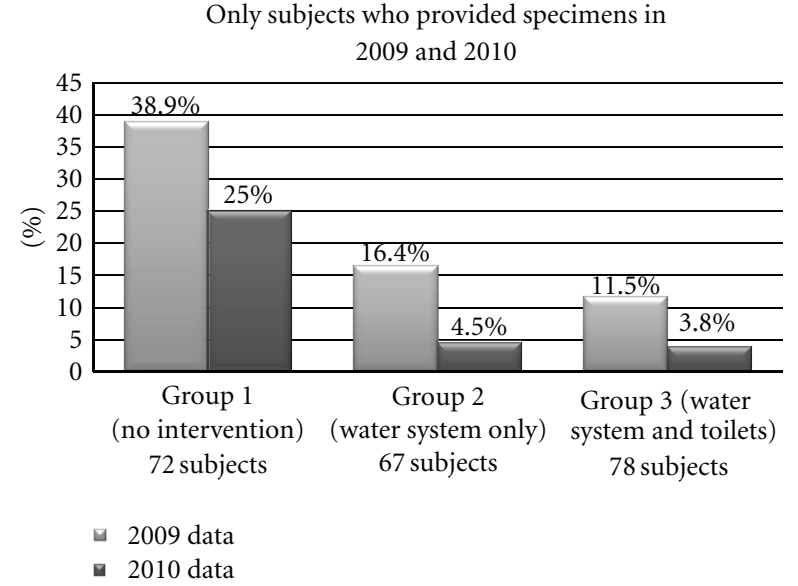

Figure 3

completely vanishes when subjects lost to follow up in 2010 are removed from the 2009 analysis.

\section{Discussion}

The present paper is a followup of the research previously reported [8] and adds support to the conclusion that access to community-based water treatment systems and flush toilets reduced the disease load in this region of Honduras. To our knowledge, these are the first studies to combine self-reported data, medical chart review, and stool immunoassays as an indicator of exposure to potential waterborne pathogens. The triangulation of these methodologies provides powerful support to what are otherwise strongly subjective and questionable measures of disease loads from waterborne pathogens.

The previously reported ethnographic data from these communities suggests a high level of understanding of the causes and prevention of diarrhea among the communities studied. The overwhelming majority (130 of 142) of the people interviewed attributed the majority of their diarrheal diseases to water and sanitation issues and improvement of the condition to improved water sources and access to flush toilets. There were also significant signs of a shift of ideations regarding drinking untreated water toward an appreciation of the importance of purified water and prohibitions against drinking untreated water with the addition of water treatment facilities and community education.

Ethnographic data found during this study suggests that, consistent with other similar work, the availability of improved water is felt by its recipients to improve a general sense of health and well-being. High levels of knowledge related to water issues exist in this area of Honduras which could be attributed to many factors including sophisticated public health efforts, high literacy rates comparable to the region, widespread health education in public schools, and the training offered by Water Missions International and other NGOs. Local indigenous belief systems appear uncommonly (mentioned in only 6 of 46 individual interviews and in none of the four focus groups) and for no one were they the basis for a preferred method of treatment.

Immunoassay evidence of decreased prevalence of waterborne parasites strongly supports the contention that community-based water treatment facilities reduce the overall stool parasite load, at least of the three protozoan species tested. Since all subjects who tested positive for either Giardia or Entameba were treated with three doses of tinidazole adjusted for age and weight, the follow-up study of all subjects who submitted stool samples initially is felt to represent the reinfection rates, in essence eliminating concerns regarding residual colonization from exposures that occurred prior to initiation of this study. Previous treatment of subjects who tested positive for any parasite creates the potential for a Hawthorne effect; however, the elevated number of positive tests initially found within the control communities would potentially bias this group more than the test groups and would tend to lessen rather than strengthen the differences found.

Also, as previously reported [8], when parasite antigens were detected in stool samples of individuals who had access to improved water sources, ethnographic investigation revealed lapses of behavior in spite of the high level of understanding of the risks associated with drinking from untreated sources. Further analysis of the interviews of subjects whose stool was positive for potential waterborne parasites suggests that risk and time management decisions rather than cultural or knowledge-based differences accounted for lapses in behavior and willingness to drink untreated water. Subjects reported that the time required to obtain treated water, sometimes a difference of only a minute or less, was too great to overcome their concerns with potential health risks associated with untreated tap water.

Multiple pathogens and inflammatory conditions cause diarrhea, making monitoring this symptom alone an inexact measure of the disease load related to water quality. Worldwide, the most common causes of diarrhea are viral infections such as the rotavirus, an ubiquitous infection that may be transmitted by personal contact. Food contamination and noninfectious inflammatory diseases add to the diarrhea prevalence. Though not precisely known, the number of diarrhea cases unrelated to waterborne pathogens is likely substantial. This means that the $52 \%$ drop in diarrhea rates noted in the previously reported community chart reviews may represent an even greater majority of the cases that could possibly be related to potential water and sanitation issues. This follow-up study strongly supports this finding and suggests that the effect where water treatment systems are maintained may even increase over time.

A comparison of the 2009 parasite test data excluding those lost to follow up a year later was dramatically different from when these individual tests were included (Figure 3). This suggests that the population that was lost to follow up significantly added to the initial rate of positive tests. This phenomenon deserves future scrutiny and incorporation into discussions of the idea of community as a social construct. If community is defined as those present at a given point in time, we see a negative impact from presence of the toilets. When we define community as those who reside in 
the geographic area for at least one year we find the exact opposite as this apparent negative impact is not detected. As this finding demonstrates, the unit of analysis remains paramount in such studies.

This combination of qualitative data, health records reviews, and immunoassays provides compelling evidence that community-based water treatment facilities with or without providing flush toilets significantly reduced the burden of diseases in the communities of Colon, Honduras. We further validate with objective measures prior work based upon self-reporting of diarrhea rates. Finally, this data suggests that interventions to provide potable water access on a community level when combined with community development efforts and sanitation can play a significant role in the reduction of mortality and morbidity from waterborne diseases and associated comorbidities.

\section{Conclusion}

Providing access to water treatment or water treatment and flush toilets significantly reduced the one-year incidence of positive test results for the three protozoan species tested. This finding combined with the previously reported ethnographic and medical chart review data provides compelling evidence that such interventions significantly reduce the disease load from waterborne pathogens within this population. Furthermore, the finding that initial results are significantly different, even in the initial round of testing, if individuals who are not followed up are eliminated from the analysis has profound methodological implications which warrant further investigation.

Adding a temporal definition of community resulted in a completely different finding regarding the impact of supplying flush toilets, demonstrating the need for precise definitions of community in future studies.

The method used here where objective measurements of health effects are coupled with more traditional anthropological tools may serve as a template for future studies in medical anthropology.

\section{References}

[1] A. Prüss-Üstün, R. Bos, F. Gore, and J. Bartram, Safer Water, Better Health: Costs, Benefits and Sustainability of Interventions to Protect and Promote Health, World Health Organization, Geneva, Switzerland, 2008.

[2] S. Boisson, W. P. Schmidt, T. Berhanu, H. Gezahegn, and T. Clasen, "Randomized controlled trial in rural Ethiopia to assess a portable water," Environmental Science and Technology, vol. 43, no. 15, pp. 5934-5939, 2009.

[3] R. J. Gelting and L. Ortolano, "A model describing performance of rural drinking water systems in Honduras," International Journal of Water Resources Development, vol. 14, no. 2, pp. 199-215, 1998.

[4] U. D. Parashar, E. G. Hummelman, J. S. Bresee, M. A. Miller, and R. I. Glass, "Global illness and deaths caused by rotavirus disease in children," Emerging Infectious Diseases, vol. 9, no. 5, pp. 565-572, 2003.

[5] D. Blum, R. N. Emeh, S. R. Huttly et al., "The Imo State (Nigeria) Drinking Water Supply and Sanitation Project, 1.
Description of the project, evaluation methods, and impact on intervening variables," Transactions of the Royal Society of Tropical Medicine and Hygiene, vol. 84, no. 2, pp. 309-315, 1990.

[6] T. Clasen, I. Roberts, T. Rabie, W. Schmidt, and S. Cairncross, "Interventions to improve water quality for preventing diarrhoea," Cochrane Database of Systematic Reviews, vol. 3, p. CD004794, 2006.

[7] L. Fewtrell and J. M. Colford Jr., "Water, sanitation, and hygiene interventions to reduce diarrhoea in less developed countries: a systematic review and meta-analysis," The Lancet Infectious Diseases, vol. 5, no. 1, pp. 42-52, 2005.

[8] Jeffery L. Deal et al., "A multidimensional measure of diarrheal disease load changes resulting from access to improved water sources in honduras," Practicing Anthropologist, vol. 32, no. 1, pp. 15-20, 2010.

[9] L. S. Garcia, R. Y. Shimizu, and C. N. Bernard, "Detection of Giardia lamblia, Entamoeba histolytica/Entamoeba dispar, and Cryptosporidium parvum antigens in human fecal specimens using the triage parasite panel enzyme immunoassay," Journal of Clinical Microbiology, vol. 38, no. 9, pp. 3337-3340, 2000.

[10] S. E. Sharp, C. A. Suarez, Y. Duran, and R. J. Poppiti, "Evaluation of the Triage Micro Parasite Panel for detection of Giardia lamblia, Entamoeba histolytica/Entamoeba dispar, and Cryptosporidium parvum in patient stool specimens," Journal of Clinical Microbiology, vol. 39, no. 1, pp. 332-334, 2001. 


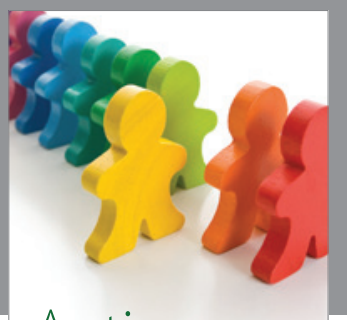

Autism

Research and Treatment
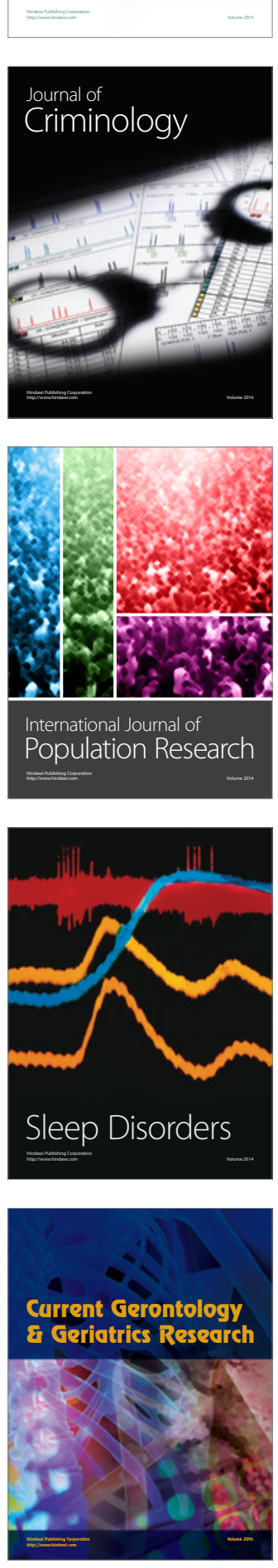
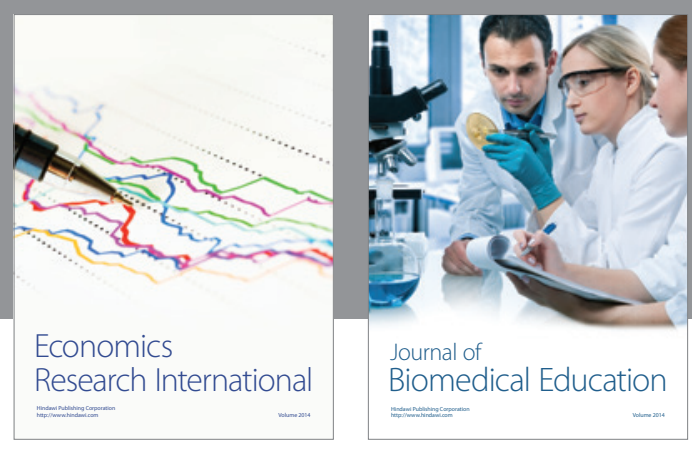

Journal of

Biomedical Education

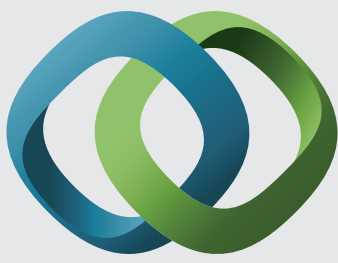

\section{Hindawi}

Submit your manuscripts at

http://www.hindawi.com
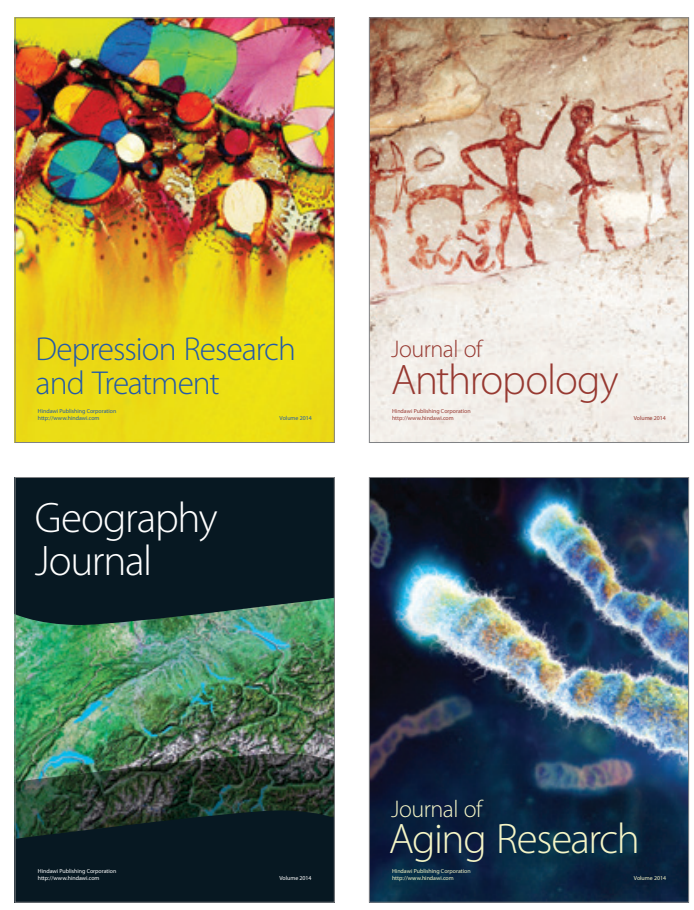

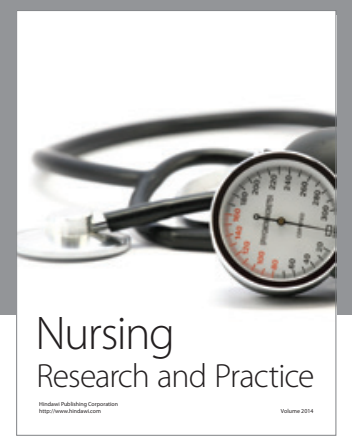

Nursing

Research and Practice

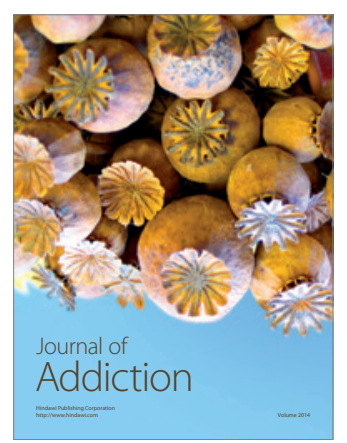

Child Development

Research

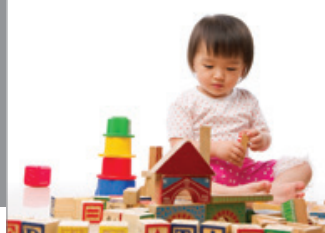

迥
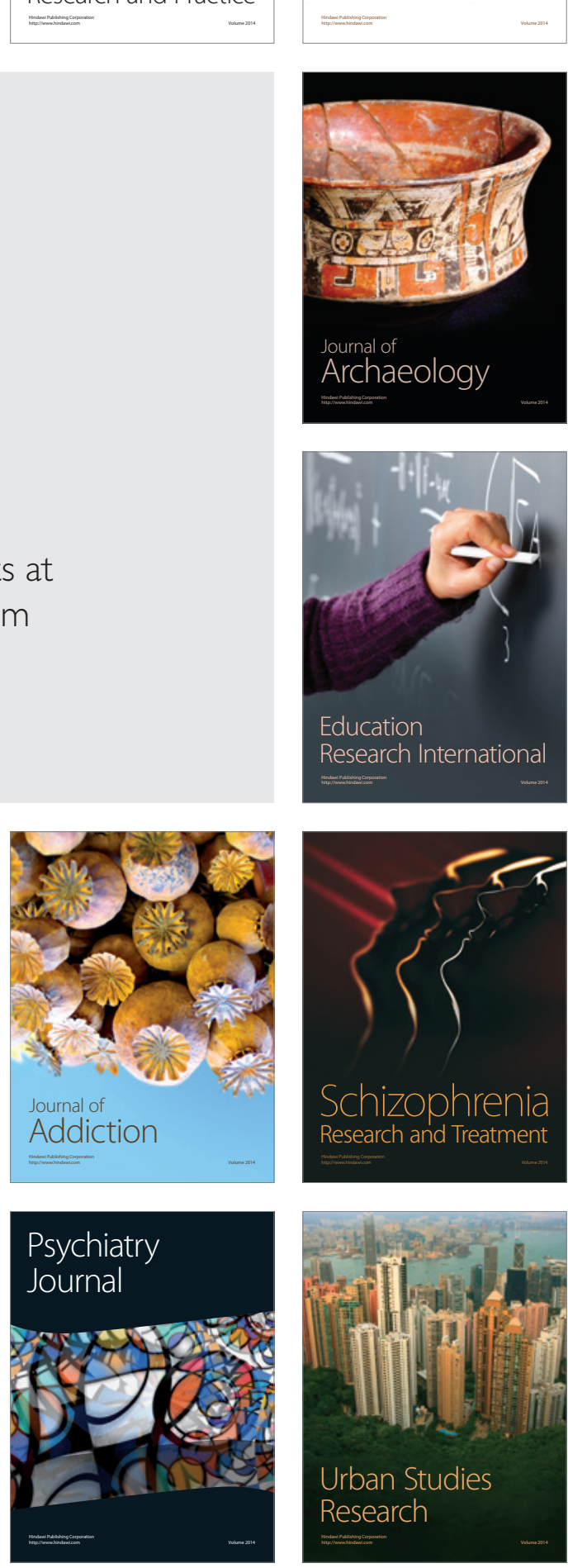